\title{
Increasing Number of People with Diabetes in Japan: Is This Trend Real?
}

\author{
Atsushi Goto ${ }^{1,2}$, Mitsuhiko Noda ${ }^{1,3}$, Manami Inoue ${ }^{4,5}$, Maki Goto $^{1}$ and Charvat Hadrien ${ }^{5}$
}

\begin{abstract}
Diabetes mellitus, especially type 2 diabetes, has been a major concern among health issues for Japanese policy requiring serious address. In this regard, the increasing number of people with diabetes in Japan over the past few decades has been regarded as a fundamental and evident problem. We herein clarify that the crude diabetes prevalence is likely to have increased mainly as a result of changes in the population distribution, namely, aging of the general population in Japan. We also predict the future trend for the number of people with diabetes according to available concrete evidence in this review.
\end{abstract}

Key words: diabetes prevalence, Japan, population aging, epidemiology

(Intern Med 55: 1827-1830, 2016)

(DOI: 10.2169/internalmedicine.55.6475)

\section{Introduction}

Diabetes mellitus, especially type 2 diabetes, has been listed as one of the major concerns among health issues for Japanese policy requiring serious address. Indeed, much attention has been paid to this disease, and the Health Japan 21 (second term) (1), the Japanese government's master plan for health policy (to which one of the authors of this article contributed as a board member of the formulation committee), also uses the number of people with diabetes as one of four diabetes-specific targets (Table) to be achieved by the year 2022 .

\section{Trends in the Diabetes Prevalence in Japan}

The increasing number of people with diabetes in Japan over the past few decades has been regarded as a fundamental problem and has been extensively discussed to date. In this context, it has been taken for granted that the absolute number of people with diabetes is increasing according to information publicized by the National Health and Nutrition Survey, Japan (NHNS-J) (2). For instance, it has been widely discussed on many occasions that the number of motor vehicles or the proportion of fat intake relative to the total energy consumption in the Japanese population might be involved in the increasing number of people with diabetes.

In a recent article (3), however, we discovered that this increasing trend might be a consequence of aging of the overall Japanese population. Indeed, a large-scale metaregression analysis of approximately 160,000 Japanese adults found that the age-standardized prevalence of diabetes has remained largely unchanged throughout the past couple of decades and was projected to remain stable during the upcoming ten years or longer, in striking contrast with the crude prevalence (Figure).

Briefly, six cohort studies [e.g., Hisayama Study (4), Funagata Study (5), and the Japan Public Health Center-based Prospective Study $(6,7)]$ and nine national health surveys [e.g., National Diabetes Surveys $(8,9)$ and NHNS-J (2)] were identified through a systematic literature search, and 161,087 adults were included in the subsequent analyses. The prevalence of diabetes was assessed using a recorded history of diabetes or, for individuals without known diabetes, either a glycated hemoglobin (HbA1c) level of $\geq 6.5 \%$ $(48 \mathrm{mmol} / \mathrm{mol})(10)$ or the 1999 World Health Organization

\footnotetext{
${ }^{1}$ Department of Diabetes Research, National Center for Global Health and Medicine, Japan, ${ }^{2}$ Department of Public Health, Tokyo Women's Medical University, Japan, ${ }^{3}$ Department of Endocrinology and Diabetes, Saitama Medical University, Japan, ${ }^{4}$ AXA Department of Health and Human Security, Graduate School of Medicine, The University of Tokyo, Japan and ${ }^{5}$ Epidemiology and Prevention Group, Research Center for Cancer Prevention and Screening, National Cancer Center, Japan

Received for publication August 30, 2015; Accepted for publication December 20, 2015

Correspondence to Dr. Mitsuhiko Noda, noda_m@saitama-med.ac.jp
} 
Table. Diabetes-specific Targets of the Health Japan 21 (Second Term) ${ }^{1}$.

\begin{tabular}{lll}
\hline Indicators & Current data & Target \\
\hline $\begin{array}{l}\text { 1. Reduction in complications (number } \\
\text { of patients newly introduced to dialysis } \\
\text { due to diabetic nephropathy) }\end{array}$ & $16,247(2010)$ & \\
$\begin{array}{l}\text { 2. Increase in the percentage of patients } \\
\text { who continue treatment }\end{array}$ & $75 \%(2000(20) 202)$ \\
$\begin{array}{l}\text { 3. Decrease in the percentage of } \\
\text { individuals with elevated blood glucose } \\
\text { levels } \\
\text { (HbA1c }>=8.4 \%)\end{array}$ & $1.0 \%(2022)$ \\
$\begin{array}{l}\text { 4. Prevent an increase in the number of } \\
\text { diabetic persons }\end{array}$ & \\
\hline
\end{tabular}
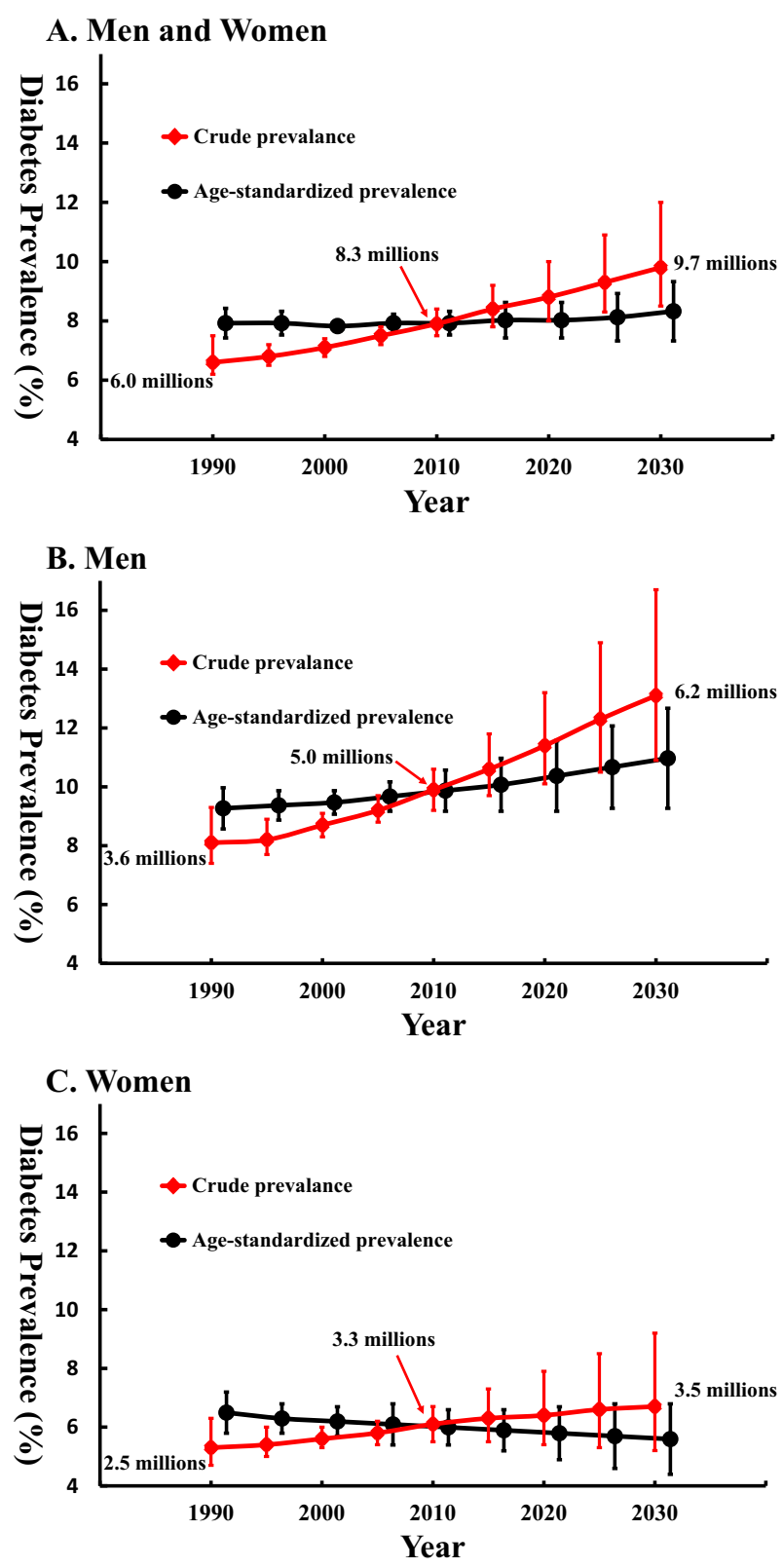

Figure. Prevalence of diabetes among Japanese adults. The age-standardized and crude prevalences of diabetes for a given year were estimated using sex- and age-specific trends in the prevalence and the Japanese population distributions for the corresponding year and the year 2010 as standardization populations, respectively. I bars indicate the $95 \%$ confidence intervals. criteria (i.e., a fasting plasma glucose level of $\geq 126 \mathrm{mg} / \mathrm{dL}$ and/or a 2-hour glucose level of $\geq 200 \mathrm{mg} / \mathrm{dL}$ in the 75 -gram oral glucose tolerance test) (11). The age-standardized and crude prevalence estimates for a given year were computed by combining the sex- and age-specific trends with the Japanese population distributions for the corresponding year and the year 2010 as standardization populations, respectively. The crude diabetes prevalence for men and women combined showed a marked increasing trend: the prevalence was $6.6 \%(6,044,000$ people) in $1990,7.1 \%$ (7,135,000 people) in 2000 , and $7.9 \%(8,295,000$ people) in 2010 and was expected to increase further to $9.8 \%(9,714,000$ people) by 2030 (3). In contrast, the age-standardized prevalence of diabetes was estimated to have remained largely unchanged over the years (1990: 7.9\%; 2000: 7.8\%; 2010: 7.9\%; and 2030: $8.3 \%$ ) (Figure A) (3). The sex-specific trends in diabetes prevalence indicated that the crude diabetes prevalence exhibited prominent increasing trends for both sexes, with an appreciably higher prevalence of diabetes in men than in women over a period of decades (Figure B, C). The sexspecific, age-standardized prevalence appeared to suggest the existence of a sex difference in the trends. The agestandardized prevalence showed a slightly decreasing trend in women (Figure C), but suggested a small upwards trend in men (Figure B).

\section{Implications and Future Directions}

What can we learn from these findings? First, the crude diabetes prevalence is likely to increase substantially, mainly as a result of the change in the population distribution. Namely, without population aging, the prevalence would remain largely constant. The main strategy for the prevention of diabetes in Japan is to supply a health guidance program consisting of lifestyle modifications to individuals with a high risk of developing type 2 diabetes (e.g., those with metabolic syndrome, impaired glucose tolerance, or impaired fasting glucose) (1). Given the fact that the increase in the prevalence of diabetes in Japan is mainly due to population aging, it is important to examine whether and to what extent the current strategy is effective for reducing the number of people with diabetes even under such a condition. In this regard, policy-related measures, such as popula- 
tion preventable fraction, might be useful for policy makers to evaluate individual strategies. More importantly, it is highly necessary to establish different approaches for the prevention of diabetes in elderly adults and middle-aged adults, since diabetes as well as the pre-diabetic condition is frequently associated with maladies that are common among seniors, such as cognitive impairment and depression (12). Hence, as intensive lifestyle modifications may not be appropriate for some elderly people, individualized preventative and management plans that incorporate the patient's comorbidity as well as values and preferences, quality of life, and life expectancy should be considered.

Second, because a substantial increase in the prevalence of diabetes is inevitable, we should reconsider the growing burden of diabetes, especially that originating from elderly people. Thus, there is an urgent need for health care professionals to develop specific management plans for diabetes per se in older patients (13). A recent analysis from the U.S. reported a potential overtreatment among older people with diabetes, suggesting that the risks of intensive treatment for glucose levels, such as severe hypoglycemia, may exceed the benefits in such patients (14). While glycemic control is important for reducing diabetes-related complications, patient safety and quality of life should also be prioritized. Accordingly, less stringent glycemic targets are generally recommended for such patients (e.g., 1\% higher HbA1c goal than that of younger patients) (15). In accordance with these notions, the Evidence-based Practice Guide for the Treatment of Diabetes in Japan 2013 edited by the Japan Diabetes Society emphasizes that the glycemic target for older patients should be based on their disease condition and other physical, mental, and social factors rather than on evidence from randomized controlled trials $(16,17)$. Therefore, an individualized approach is essential for the management of diabetes in elderly people.

Third, there was a remarkable difference between men and women regarding the prevalence of diabetes, with a higher prevalence of diabetes in men than in women over time. In addition, the prevalence is expected to slightly decrease in women, but to increase in men. This might be explained by the higher prevalence of obesity in men than in women and an increasing trend in the mean body mass index (BMI) among men, especially for middle-aged men (2). In contrast, there is a slight decreasing trend in the mean BMI among women, especially young women. This appears to suggest that body weight management through lifestyle modification may be an effective preventative strategy to decrease the prevalence of diabetes in Japan, especially for middle-aged men.

Finally, our projection of the number of people with diabetes in 2030 was $9,714,000$ people, which is slightly lower than the target $(10,000,000$ people in 2022) in the Health Japan 21 (second term) (1). Of note, we estimated this number according to studies identified in our systematic review (3), whereas the target was developed by examining the trends in national surveys (1). Although it remains to be clarified whether estimates based on a systematic review or national surveys better reflect the trends in diabetes prevalence, we believe that the comprehensive summaries of evidence identified through this systematic review are likely to be helpful for developing Japanese health policy.

\section{Conclusion}

In conclusion, our recent analysis suggested that the absolute number of people with diabetes in Japan will substantially increase over the next decades, mainly due to aging of the nation. The present analysis highlights the importance of taking population structure into account whenever the trends of disease prevalence or the number of people suffering from the disease are considered, for which diabetes is not an exception. At the same time, we would like to underscore the importance of establishing countermeasures against health problems based on firm and comprehensive evidence.

\section{Author's disclosure of potential Conflicts of Interest (COI).}

Mitsuhiko Noda: Honoraria, Taisho Toyama Pharmaceutical; Research funding, Sanwa Kagaku Kenkyusho and Takeda Pharmaceutical.

\section{References}

1. Ministry of Health, Labour and Welfare. A basic direction for comprehensive implementation of national health promotion. 2012 [Internet]. [cited 2015 Aug. 16]. Available from: http://www.mhlw. go.jp/file/06-Seisakujouhou-10900000-Kenkoukyoku/0000047330.p df

2. Ministry of Health, Labour and Welfare. National health and nutrition survey [Internet]. [cited 2015 Aug. 16]. Available from: http:// www.mhlw.go.jp/bunya/kenkou/kenkou_eiyou_chousa.html

3. Charvat H, Goto A, Goto M, et al. Impact of population aging on trends in diabetes prevalence: a meta-regression analysis of 160,000 Japanese adults. J Diabetes Investig 6: 533-542, 2015.

4. Ohmura T, Ueda K, Kiyohara Y, et al. Prevalence of type 2 (noninsulin-dependent) diabetes mellitus and impaired glucose tolerance in the Japanese general population: the Hisayama Study. Diabetologia 36: 1198-1203, 1993.

5. Sekikawa A, Tominaga M, Takahashi K, et al. Prevalence of diabetes and impaired glucose tolerance in Funagata area, Japan. Diabetes Care 16: 570-574, 1993

6. Kabeya Y, Kato M, Isogawa A, et al. Descriptive epidemiology of diabetes prevalence and HbA1c distributions based on a selfreported questionnaire and a health checkup in the JPHC diabetes study. J Epidemiol 24: 460-468, 2014.

7. Noda M, Kato M, Takahashi Y, et al. Fasting plasma glucose and 5-year incidence of diabetes in the JPHC diabetes study: suggestion for the threshold for impaired fasting glucose among Japanese. Endocr J 57: 629-637, 2010.

8. Ministry of Health. National diabetes survey, 1997 [Internet]. [cited 2015 Aug. 16]. Available from: http://www.mhlw.go.jp/touke i/kouhyo/indexkk_4_1.html

9. Ministry of Health, Labour and Welfare. National diabetes survey, 2002 [Internet]. [cited 2015 Aug. 16]. Available from: http://www. mhlw.go.jp/shingi/2004/03/s0318-15.html\#tyosa

10. Kashiwagi A, Kasuga M, Araki E, et al. International clinical harmonization of glycated hemoglobin in Japan: from Japan Diabetes Society to National Glycohemoglobin Standardization Program 
values. J Diabetes Invest 3: 39-40, 2012.

11. Alberti KG, Zimmet PZ. Definition, diagnosis and classification of diabetes mellitus and its complications. Part 1: diagnosis and classification of diabetes mellitus provisional report of a WHO consultation. Diabet Med 15: 539-553, 1998.

12. Mineyama T, Noda M. Diabetes and depression. Nippon Ronen Igakkai Zasshi (Jpn J Geriatr) 50: 744-747, 2013 (in Japanese).

13. Sinclair A, Dunning T, Rodriguez-Mañas L. Diabetes in older people: new insights and remaining challenges. Lancet Diabetes endocrinol 3: 275-285, 2015.

14. Lipska KJ, Ross JS, Miao Y, Shah ND, Lee SJ, Steinman MA. Potential overtreatment of diabetes mellitus in older adults with tight glycemic control. JAMA Intern Med 175: 356-362, 2015.
15. Inzucchi SE, Bergenstal RM, Buse JB, et al. Management of hyperglycemia in type 2 diabetes, 2015: a patient-centered approach: update to a position statement of the American Diabetes Association and the European Association for the Study of Diabetes. Diabetes Care 38: 140-149, 2015.

16. Tajima $N$, Noda $M$, Origasa $H$, et al. Evidence-based practice guideline for the treatment for diabetes in Japan 2013. Diabetol Int 6: 151-187, 2015.

17. The Japan Diabetes Society. Diabetes (and bone metabolism) in the elderly. In: Evidence-based Practice Guide for the Treatment of Diabetes in Japan. Nankodo, Tokyo, 2013: 245-261 (in Japanese).

(C) 2016 The Japanese Society of Internal Medicine

http://www.naika.or.jp/imonline/index.html 